\title{
Chronic pain during pregnancy: a review of the literature
}

This article was published in the following Dove Press journal:

International Journal of Women's Health

\author{
Shona L Ray-Griffith ${ }^{1,2}$ \\ Michael P Wendel ${ }^{2}$ \\ Zachary N Stowe ${ }^{3}$ \\ Everett F Magann ${ }^{2}$ \\ 'Department of Psychiatry, \\ University of Arkansas for Medical \\ Sciences, Little Rock, AR, USA; \\ ${ }^{2}$ Department of Obstetrics and \\ Gynecology, University of Arkansas \\ for Medical Sciences, Little Rock, \\ AR, USA $;{ }^{3}$ Department of Psychiatry, \\ University of Wisconsin-Madison, \\ Madison, WI, USA
}

Background and purpose: The majority of the reviews and studies on chronic pain in pregnancy have primarily focused on the pharmacological and non-pharmacological treatment options. The purpose of our review was to identify evidence-based clinical research for the evaluation and management of preexisting chronic pain in pregnancy, chronic pain associated with pregnancy, and chronic pain in relation to mode of delivery.

Methods: A literature search was undertaken using the search engines PubMed, CINAHL, EBSCOhost, and Web of Science. Search terms used included "chronic pain" AND "pregnant OR pregnancy" OR "pregnancy complications” from inception through August 2016.

Results: The basis of this review was the 144 articles that met inclusion criteria for this review. Based on our review of the current literature, we recommend 7 guidelines for chronic pain management during and after pregnancy: 1) complete history and physical examination; 2) monitor patients for alcohol, nicotine, and substance use; 3 ) collaborate with patient to set treatment goals; 4) develop a management plan; 5) for opioids, use lowest effective dose; 6) formulate a pain management plan for labor and delivery; and 7) discuss reproductive health with women with chronic pain.

Conclusion: The management of chronic pain associated with pregnancy is understudied. Obstetrical providers primarily manage chronic pain during pregnancy. Some general guidelines are provided for those health care providers until more information is available.

Keywords: chronic pain, pregnancy, pregnancy complications, chronic pain in pregnancy, guidelines for pain in pregnancy, pain management in pregnancy

\section{Introduction}

Chronic pain impacts over 100 million Americans and is the most common cause of long-lasting disability. ${ }^{1}$ Conspicuously, women are more impacted by chronic pain disorders than men. Health care providers are frequently faced with the difficulties of managing chronic pain conditions that were present prior to, during, or after pregnancy. Pain thresholds in healthy women without chronic pain have been shown to increase throughout pregnancy peaking just prior to delivery. ${ }^{2}$ Animal models have shown that naltrexone, an opioid antagonist, can block these findings. ${ }^{3}$ It is unclear how these findings may translate to women with chronic pain or opioid exposure as such individuals often have hyperanalgesia, allodynia, and/or decreased pain thresholds at baseline.

Back pain is a frequent ailment encountered in pregnancy, and a frequently used standard textbook for obstetrics training, Williams' Obstetrics, provides few guidelines for the management of acute back pain during pregnancy. ${ }^{4}$ The textbook cites "evidence-based clinical research directing care is limited" and provides even less education concerning the diagnosis and/or management of chronic back pain. ${ }^{4}$ Health care providers caring for obstetrical patients have inadequate training and limited
Correspondence: Everett F Magann Department of Obstetrics and Gynecology, University of Arkansas for Medical Sciences, 430I W Markham Street, Slot \# 518, Little Rock, AR 72205 , USA

Tel + I 5016868345

Fax + I 50I 5267820

Email efmagann@uams.edu
International Journal of Women's Health 2018:10 153-164

(c) (1) (8) ๑ 2018 Ray-Griffith et al. This work is published and licensed by Dove Medical Press Limited. The full terms of this license are available at https//www.dovepress.com/terms.php

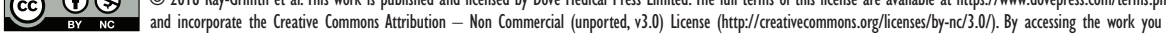
hereby accept the Terms. Non-commercial uses of the work are permitted without any further permission from Dove Medical Press Limited, provided the work is properly attributed. For peminsion for commercial use of this work, please see paragraphs 4.2 and 5 of our Terms (https://www.dovepress.com/terms.php). 
time to manage patients with chronic pain. Pain management teams and clinics often discharge or decline to manage women during pregnancy, and transition of care is often referred to the obstetrical team. The United States Opioid Epidemic has recently underscored the risk of prescription drug abuse for patients as well as the role that health care providers have in monitoring and educating patients for substance and alcohol use disorders. The lack of evidencebased treatment guidelines and limited formal training and expertise in the management of chronic pain places pregnant women at risk to receive suboptimal care.

The majority of published reviews have focused on the pharmacological or non-pharmacological approaches, rather than on a broader scope of how to approach chronic pain during pregnancy. The purpose of this review is to identify evidence-based clinical research for the evaluation and management of preexisting chronic pain during pregnancy, chronic pain that has been associated with pregnancy, and chronic pain in relation to mode of delivery (ie, vaginal or cesarean) as well as provide guidance to address the broader clinical care of this population. The information obtained will provide the basis for clinical guidelines for the management of chronic pain disorders by obstetrical care providers during the perinatal period. Our goal is to help guide clinicians in management of these patients; thus, an in-depth discussion of the perinatal effects of in utero pharmacological exposure is beyond the scope of the review.

\section{Methods}

A literature search was undertaken using the search engines PubMed, CINAHL, EBSCOhost, and Web of Science. Search terms used included "chronic pain/therapy" AND "pregnant OR pregnancy" OR "pregnancy complications" from inception through April 7, 2016. Abstracts were limited to those in English. There were 200 abstracts identified and reviewed by two independent reviewers. One independent reviewer then examined the full research article corresponding to chronic pain/therapy and pregnancy for relevance. References for such articles were screened for additional applicable research.

Of the 200 abstracts identified, 15 were duplicates; 3 were not available in English; 2 could not be located; and 47 were chosen for full manuscript review. After screening the reference list of each identified article, an additional 115 articles were identified, of which, 18 articles could not be located. The basis of this review includes 144 articles (Figure 1), including 47 cohort studies, 35 reviews, 28 case reports, 13 randomized clinical trials, 10 case series, 9 case control studies, 1 comparative analysis, and 1 qualitative interview.

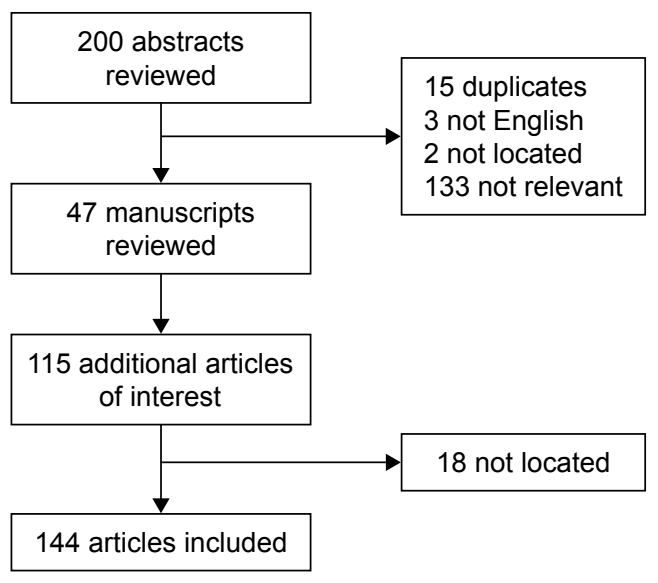

Figure I Preexisting chronic pain disorder during pregnancy.

\section{Preexisting chronic pain disorder during pregnancy}

The overall prevalence of pregnant women with preexisting chronic pain disorders is unknown. Likewise, the general course of chronic pain conditions during pregnancy has not been studied. Preexisting chronic pain disorders have a negative impact on pregnancy and are associated with increased sick leave use, insomnia, and depressive symptoms during pregnancy. 5,6

Numerous reviews of both the prescription and nonprescription pharmacological treatment of chronic pain have been published. ${ }^{7-13}$ As previously mentioned, the purpose of this review is not to discuss treatment options in-depth, but we feel it is important to discuss opioids and acetaminophen as both options have received recent scrutiny. Opioid prescriptions in the first trimester increased by 33.9\% from 1995 to 2009 for non-cancer pain diagnoses indicating that pain syndromes during pregnancy are being increasingly treated with prescription opioids. ${ }^{14}$ This finding is not surprising as opioids are often second-line treatment options during pregnancy, after acetaminophen, due to the established efficacy in acute conditions and limited reproductive safety data of other pharmacological options. ${ }^{15}$ Coinciding with the increase in prescription opioid use is an increasing rise in rates of infant with neonatal abstinence syndrome (NAS), a syndrome related to opioid exposure in utero that is characterized by difficulties with feeding and sleeping as well as central nervous system dysfunction. ${ }^{16} \mathrm{~A}$ single source, The Canadian Guideline for the Use of Opioids in the Treatment of Chronic Noncancer Pain, has published treatment guidelines that recommend the following: 1) opioids should be tapered and discontinued or prescribed at the lowest effective dose; 2) in the postpartum period, codeine use should be avoided or limited to 4 days; 3) women should 
be managed by perinatologists; and 4) women with opioid use disorders should be referred for appropriate treatment. ${ }^{17}$ The formulation of these guidelines is influenced by the potential addictive and teratogenic effects of opioids (ie, cardiovascular birth defects, neural tube defects, hydrocephaly, glaucoma, NAS, gastroschisis, and fetal death) ${ }^{18-21}$ as well as the correlation of codeine with planned cesarean delivery, postpartum hemorrhage, ${ }^{22}$ and infant death in a breastfeeding mother who is a CYP2D6 ultra-rapid metabolizer. ${ }^{23}$ No opioid is given preference in these guidelines owing to lack of data supporting individual medications. Methadone has the largest amount of reproductive safety data secondary to its use in medication-assisted treatment programs for pregnant women with opioid use disorders. Methadone is also an effective treatment for chronic pain, and a few studies have compared obstetrical and neonatal outcomes between methadone for chronic pain disorders versus opioid use disorder during pregnancy. Pregnant women receiving methadone for chronic pain had better infant growth but more neonatal morbidity and preterm birth rates compared to women with an opioid use disorder. ${ }^{24}$ In two studies comparing rates of NAS with prescription opioid use and not illicit opioid use, NAS occurred in $5.6 \%{ }^{25}$ and $11 \%{ }^{24}$ of exposed neonates, rates lower than infants born to mothers in opioid treatment programs on maintenance medications (ie, methadone or buprenorphine). No evidence is available for the treatment of chronic pain during pregnancy using buprenorphine. In conclusion, reproductive safety data of opioids are limited and often conflicted. Jones et al discussed the methodological limitations of current research and the need for future research on the use of opioids in pregnancy for chronic pain disorders. ${ }^{9}$

Acetaminophen is the most common nonprescription medication recommended during pregnancy to treat pain and has been recently associated with increased risk for respiratory, testicular, attention-deficit/hyperactive-like behavioral, and autism spectrum disorders. ${ }^{24-30}$ These results have questioned the reproductive safety profile of acetaminophen; however, it remains one of the most commonly used medications during pregnancy, specifically for pain indications.

A variety of non-pharmacological treatments for chronic pain also exists, but data during the perinatal period are limited. Evidence supporting the use of spinal cord stimulation for chronic regional pain syndrome and other chronic pain states is primarily based on case reports and case series that demonstrate conflicting obstetrical and neonatal effects. ${ }^{31-41}$ Three case reports of intrathecal baclofen pumps used in pain management during pregnancy without obstetrical or neonatal complications have been reported. ${ }^{42-44}$
Conservative guidelines do not recommend the use of transcutaneous electrical nerve stimulation (TENS) during pregnancy due to potential legal consequences with an adverse pregnancy outcome, but liberal guidelines suggest that the use of TENS is acceptable but should be avoided over the maternal abdomen or pelvic areas. ${ }^{45}$ Acupuncture is also often suggested, but the literature search found no studies supporting its use.

We identified a number of articles discussing specific pain conditions during pregnancy, such as migraines, rheumatoid arthritis, sickle cell disease, Ehlers-Danlos syndrome, and vulvodynia. Each is discussed in more detail later in the paper. Additionally, our literature search found a case report of intrathecal opioids for a pregnant woman with tuberous sclerosis $^{46}$ as well as reviews of irritable bowel syndrome during pregnancy, ${ }^{47}$ complex regional pain syndrome during pregnancy, ${ }^{48}$ and the development of acute pain on existing chronic pain during pregnancy. ${ }^{49}$

\section{Headaches}

Headaches and more specifically migraines are present in $16 \%-18 \%$ of women of reproductive age, but the prevalence during pregnancy is unknown. ${ }^{50,51}$ Most experts agree that the course of headaches (tension-type, migraines, or a combination) during pregnancy is variable. ${ }^{52,53}$ Studies have shown that migraines largely improve or remit during pregnancy with an initial occurrence during pregnancy in $1.3 \%$ of women and in the postpartum period in $4.5 \%$ of women. ${ }^{54}$ Pregnant women with headaches have been reported to have a greater rate of preterm delivery, gestational hypertension, and preeclampsia. ${ }^{55,56}$

Multiple review articles have been written summarizing the management of headaches, including migraines, during pregnancy, and women who are breastfeeding, ${ }^{57-59}$ Jürgens et al reviewed the treatment of cluster headaches during the perinatal period. ${ }^{60}$ Management includes both acute and preventative techniques. The acute management of headaches and migraines during pregnancy primarily utilizes non-pharmacological measures initially, such as relaxation techniques, appropriate duration of sleep, stress management, massages, application of cold, avoidance of triggers, and biofeedback. A combination of biofeedback, relaxation training, and physical therapy has also been successfully used in pregnancy. ${ }^{61}$ Pharmacological options, in order of level of recommendation, for acute management include acetaminophen, triptans, antiemetics, and opiates. In a large prospective, observational study, triptan (ie, sumatriptan, rizatriptan, zolmitriptan, eletriptan, naratriptan, almotriptan) use in the 6 months prior to pregnancy was associated with 
an increased risk of stillbirth. ${ }^{62}$ The same study found that triptan use during pregnancy was not associated with an increased rate of major congenital malformations, while use in the second and third trimester was associated with an increased risk of atonic uterus and blood loss $>500 \mathrm{~mL}$ during labor. ${ }^{62}$ Maternal prescription of a sumatriptan during pregnancy was not associated with increased teratogenic risk $^{63}$ but was associated with an increased risk of preterm delivery. ${ }^{64}$ An examination of children with in utero exposure to triptans (ie, sumatriptan, rizatriptan, zolmitriptan, eletriptan, naratriptan, almotriptan, frovatriptan) at 3 years of age showed a positive association with externalizing behaviors but no association with altered or delayed psychomotor function, communication, or temperament development. ${ }^{51,65}$ Metoclopramide with or without acetaminophen can also be used to treat both acute migraines as well as accompanying nausea without adverse perinatal effects. ${ }^{66}$ Evidence supporting the use of other antiemetics for acute treatment of migraine was not found.

For migraine sufferers, preventative treatment, in order of recommendation, during the antenatal period includes tricyclic antidepressants, topiramate, magnesium, and botulinum toxin. Evidence supporting the efficacy of any option is limited during pregnancy, and treatment recommendations are based on reproductive safety data. Botulinum toxin is approved by the FDA to treat chronic migraines and has been studied in the treatment of various chronic pain disorders. ${ }^{67}$ The use of botulinum toxin has been discussed with recommendations that state pregnant women should make an informed decision about the use of botulinum toxin during the perinatal period after reviewing the potential risks and benefits to the pregnancy and fetus. ${ }^{67}$

\section{Rheumatoid arthritis}

The prevalence of rheumatoid arthritis during pregnancy is unknown. The pregnancy course of rheumatoid arthritis varies, but the majority of patients with RA improve during the antenatal period with a subsequent relapse in the postpartum period. ${ }^{68,69}$ Preconception counseling for individuals with rheumatoid arthritis is recommended given the teratogenic potential of treatment options. However, the overall impact of rheumatoid arthritis on obstetrical and neonatal outcomes is unknown. Three reviews have summarized the pharmacological management of rheumatoid arthritis during the perinatal period with a review of commonly used medications that are recommended for use during the perinatal period (ie, chloroquine, hydroxychloroquine, sulfasalazine, azathioprine, cyclosporine, corticosteroids, NSAIDS) ${ }^{70-72}$ and glucocorticoids are the most commonly used. ${ }^{73}$

\section{Sickle cell disease}

Although the prevalence of sickle cell disease during pregnancy is unknown, exacerbations can occur due to increased oxygen consumption and decreased functional residual capacity of the lungs during gestation, predisposing patients to sickling, vaso-occlusive pain, and sickle cell crises. ${ }^{74}$ Early reports of pregnant women with sickle cell disease demonstrated an association with spontaneous abortions, stillbirths, and pregnancy-related maternal death: ${ }^{75,76}$ however, medical advancements have contributed to improved obstetrical and neonatal outcomes. ${ }^{77,78}$ Treatment during pregnancy is primarily supportive with use of medications on a case-by-case basis. Opioids have been a mainstay in the treatment of sickle cell pain crises, while hydroxyurea should be avoided due to its possible teratogenicity. ${ }^{74,79}$ Prophylactic red blood cell transfusions have no obstetrical or neonatal advantage when compared to an as-needed use for transfusions, except for a decrease in the number of painful crises. ${ }^{80}$ Adequate hydration and avoidance of triggers are helpful in the prevention of sickle cell crises and other sequelae of sickle cell disease.

\section{Ehlers-Danlos syndrome}

Ehlers-Danlos syndrome is a heritable connective tissue disorder affecting collagen and leading to hypermobility of joints and skin and chronic debilitating musculoskeletal disorders. The prevalence of pregnant women with the syndrome is unknown. The condition can be exacerbated in women who become pregnant secondary to the additional joint laxity and increased maternal weight of pregnancy. In addition, labor can progress rapidly. ${ }^{81}$ Impact on neonatal outcomes is unknown. Management is primarily with acetaminophen, opioids, and short courses of steroids. ${ }^{7,81}$

\section{Vulvodynia}

The prevalence of vulvodynia during the perinatal period is unknown. The course is also largely unknown but a few investigations, detailed later, have been completed. ${ }^{82}$ A qualitative study found that women with vulvodynia minimized their pain severity during preconception timing and often discontinued medications prior to conception with optimism about the possibility of improved pain during pregnancy. ${ }^{83}$ While pregnant, all women reported increased anxiety about pain; however, no clear consensus of pain course was found during pregnancy and in the postpartum period. ${ }^{83}$ In a retrospective case-cohort study, vulvodynia did not impact likelihood of pregnancy or pregnancy outcomes, but women with vulvodynia were more likely to have a cesarean section and increased postpartum pain with a vaginal delivery that resulted in a laceration or an episiotomy. ${ }^{84}$ 


\section{Chronic pain associated with pregnancy}

Clinical practice dictates that low back pain is a common occurrence during pregnancy that begins between the fifth and seventh months, and research illustrates that low back pain and pelvic pain occur in $71.7 \%$ of pregnancies. ${ }^{85}$ Back pain during pregnancy is considered to be lumbar pain, pelvic pain, or a combination of both with a few studies investigating differences between the types of pain. Hip and foot pain are also common during the perinatal period but not routinely investigated. ${ }^{86}$

Low back pain during pregnancy is associated with age, ${ }^{87}$ Caucasian and African-American race, ${ }^{87,88}$ and the presence of low back pain before pregnancy, during menstruation, and during a previous pregnancy ${ }^{88}$ On the other hand, Hispanic ethnicity $; 8$ use of oral contraceptives, caffeine, tobacco, and exercise $;{ }^{87}$ prepregnancy body weight $;{ }^{87}$ parity $;{ }^{87}$ and history of infertility with hormone therapy are not associated with an increased risk. ${ }^{87}$ Low back pain causes moderate disability and about $10 \%$ of patients will take off time from work. ${ }^{87,89}$ The occurrence of low back pain during pregnancy increases the risk of low back pain later in life and in subsequent pregnancies. ${ }^{90}$

The course of low back pain during the antenatal period has not been documented; however, recovery in the postpartum period occurs in $58.3 \%$ of first, $66.4 \%$ of second, and $70.7 \%$ of third pregnancies. ${ }^{85}$ In a prospective study investigating lumbar pain, pelvic girdle pain, and combined pain during pregnancy, results showed that 1 out of 5 women with pelvic girdle pain or combined pain had persistent pain 3 months postpartum in comparison to 1 out of 29 with lumbar pain. ${ }^{91}$ Pelvic pain persists at a rate of about $8.5 \%$ at 2 years postpartum, ${ }^{92}$ and low back pain persists at a rate of about $21.1 \%$ at 2 and 3 years postpartum..$^{93,94}$

Chronicity of antenatal back pain that continues into the postpartum period is associated with a previous history of back pain while non-pregnant or pregnant, ${ }^{93}$ chronic pelvic girdle pain, or a combined pelvic girdle/low back pain that includes muscle weakness in the large pelvic and dorsal muscles, ${ }^{94}$ work dissatisfaction, ${ }^{91}$ early onset of symptoms in the pregnancy ${ }^{91,93}$ older age, ${ }^{91,93}$ younger age,${ }^{89}$ increased sick day use during pregnancy ${ }^{89}$ higher parity ${ }^{89}$ higher body mass index,${ }^{89}$ higher weight gain during the perinatal period,,${ }^{93}$ an inability to return to prepregnancy weight postpartum, ${ }^{93}$ and lower endurance of the back flexors. ${ }^{91}$ Physical activity level prior to pregnancy does not impact one's risk of developing chronic low back pain and pelvic pain in the postpartum period. ${ }^{85}$

Herniated lumbar discs are one isolated cause of back pain during pregnancy, occurring at an incidence rate of 1 in
10,000 that should be recognized. ${ }^{95}$ Warning signs include predominant radicular leg pain, motor signs of limb paresis, or abnormalities in reflex response associated with limiting sciatic pain radiation during a straight leg-raising maneuver..$^{95}$ An operative delivery is recommended. ${ }^{95}$

Treatment of back pain during pregnancy includes both pharmacological and non-pharmacological approaches. Pharmacological options include low-dose aspirin, acetaminophen, and short use of NSAIDS. ${ }^{96}$ Non-pharmacological treatment options include patient education with or without physiotherapy, ${ }^{97}$ mechanical supports, TENS; exercise, craniosacral therapy, osteomanipulative therapy, multimodal intervention, and acupuncture ${ }^{98}$ Data are conflicting regarding efficacy of the aforementioned options, and $75 \%$ of providers will not recommend any formal treatment. ${ }^{87,88}$ A 2013 Cochrane Review found moderate-quality evidence supporting acupuncture and exercise for pelvic or lumbopelvic pain and low-quality evidence supporting exercise for low back pain. ${ }^{99}$ Meanwhile, a 2015 Cochrane Review by the same authors found low-quality evidence supporting the role of exercise in reducing low back pain and moderate-to-low quality evidence that exercise improves functional disability. ${ }^{100}$ The latter review also found that acupuncture, craniosacral therapy, osteomanipulative therapy, and multmodal intervention may be of benefit to pregnant women with pelvic pain. ${ }^{100}$ A systematic review for physical therapy found no strong evidence in support of therapeutic effects; ${ }^{101}$ however, the same authors found that physical therapy is an effective treatment for pelvic girdle pain and adding specific stabilizing exercises provides a potential advantage. ${ }^{102}$ Acupuncture is also effective when compared to physiotherapy, and both acupuncture and physiotherapy are superior to education only. ${ }^{103}$ Pelvic support belts provided no advantage over education and exercise. ${ }^{104}$ Likewise, there is no benefit to pelvic girdle pain with an education group, home exercise group, or supervised exercise group when participants are provided a non-elastic sacroiliac belt. ${ }^{105}$ Group education by itself has also been found to be ineffective. ${ }^{106}$ Case studies support the use of instrumentassisted soft tissue mobilization ${ }^{107}$ as well as acupuncture combined with opioids. ${ }^{108}$

\section{Chronic pain associated with mode of delivery (vaginal vs cesarean)}

While some studies have shown that the risk of chronic pain after pregnancy is rare at $0.3 \%,{ }^{109}$ other studies have shown a more common prevalence rate of $10 \% .{ }^{110}$ Studies have shown that delivery mode is not related to the risk of experiencing pain at 8 weeks, ${ }^{111} 3$ months, ${ }^{112}$ and 2 years. ${ }^{113}$ On the 
other hand, mode of delivery may impact the prevalence as rates are $0.6 \%-22 \%$ following caesarean delivery and $1 \%-10 \%$ with vaginal delivery. ${ }^{114-123}$ In the loan study investigating deliveries with an episiotomy, up to $12.8 \%$ of patients had chronic pain lasting a minimum of 5 months. ${ }^{124}$

Lavand'homme has published extensively about chronic pain after delivery and noted five key points: 1) incidence of persistent postsurgical pain after childbirth is lower than similar surgical procedures; 2) pain characteristics are poorly detailed; 3) after a cesarean delivery, pain is primarily low-intensity neuropathic pain; 4) the extent of trauma is not predictive of pain severity; and 5) the aforementioned findings suggest that protective antinociceptive mechanisms occur during the perinatal period. ${ }^{15,125,126}$ Others have echoed the prevalence of neuropathic pain after cesarean delivery. ${ }^{127}$

Notable risk factors for postpartum chronic pain include a history of previous chronic pain disorder and higher postoperative pain severity ${ }^{10,111,119,121,128}$ but not epidural analgesia. ${ }^{129}$ Use of general anesthesia, non-private insurance status, emergency cesarean delivery, and psychological indication for cesarean delivery are risk factors noted with caesarean delivery only. ${ }^{109,117,119,130,131}$ In the lone genetic study, polymorphisms of the ATP-binding cassette sub-family B member-1 gene were not associated with the increased risk for development of chronic pain following a cesarean section, but a trend was found for women with the $\mathrm{T}$ allele of $\mathrm{tC} 3435 \mathrm{~T}$ polymorphism. ${ }^{132}$

The relationship between analgesic methods (ie, intrathecal clonidine, wound infiltration, transversus abdominal plane block, intravenous ketamine, oral gabapentin, and pregabalin) and development of chronic pain following an operative abdominal delivery in the postpartum period have been discussed extensively and the following surgical techniques have been implicated as risk factors: larger surgical incisions with increased risks for lateral nerve entrapment and neuromas, uterine exteriorization and parietal peritoneal closure, ${ }^{121}$ and repeated surgical procedures as a cause for hypersensitization. ${ }^{133}$ Two articles compared patients based on surgical technique, Pfannenstiel or Misgav-Ladach, ${ }^{134,135}$ and results favored the Misgav-Ladach technique. ${ }^{134,135}$ Multiple Pfannenstiel incisions have been shown to predict chronic pain at 12 months. ${ }^{131}$ Postoperative treatment of pain also impacts the development of postpartum chronic pain as higher doses of local anesthetic and the use of anti-inflammatory medicines postoperatively decreased the incidence of chronic pain at 3 months. ${ }^{130}$ To decrease post-cesarean pain, a double-blind placebo-controlled trial compared intravenous magnesium sulfate in low and high doses with a control group and observed that short-term pain and long-term pain ( 6 weeks) were similar between the magnesium arms and a control group of women. ${ }^{136}$ The impact of postpartum chronic pain on neonatal outcomes or women's quality of life is largely unstudied, but one investigation found a negative impact on sexual and nonsexual activities. $^{110}$

Our literature search failed to find any discussion on the preferred treatment options for postpartum chronic pain with exception of the neuromas. Neuromas of the iliohypogastric and ilioinguinal nerves are often the source for chronic pain, and treatment options include nerve blocks, neurectomy, or decompression of involved peripheral nerves. ${ }^{137,138}$ Although oxytocin has not been studied as a potential treatment for pain, animal studies have implicated a role of oxytocin in the alleviation of pain in the immediate postpartum period. ${ }^{139}$

A rare source of postpartum chronic pain is pubic symphysis diastasis. After a vaginal delivery, diagnosis is suspected with the following: pain immediately postpartum, pain exacerbation with weight bearing, symphyseal tenderness, and an interpubic gap greater than $10 \mathrm{~mm} .{ }^{140}$ The exact cause and prevalence are unknown. ${ }^{141,142}$ It is thought that relaxin and progesterone levels may be associated with development of pubic symphysis diastasis; however, relaxin level in pregnancy does not correlate with either degree of symphyseal distention or pain level. ${ }^{143}$ Evidence-based treatment is derived from a number of case reports, ${ }^{142,144-146}$ and patients are typically managed conservatively with or without analgesia. Small studies have shown success with physical therapy or chiropractic management, ${ }^{148}$ surgical stabilization, ${ }^{144,148}$ and spinal cord stimulation when other treatments have failed. ${ }^{149}$ A small retrospective chart review of 14 patients showed seven with no benefit of corticosteroid injections. ${ }^{150}$

\section{Summary}

Chronic pain disorders are a major problem during the perinatal period, and health care professionals have received limited formal training. Previous data have largely focused on pharmacological management during pregnancy, primarily with the use of opiates. Our literature search found that the majority of information focuses on the management of preexisting chronic pain conditions during pregnancy. A moderate amount of literature describes the risk of developing a chronic pain disorder in the postpartum period due to mode of delivery; however, data detailing chronic pain conditions that develop during pregnancy are scant. Research detailing the impact of pain on obstetrical and neonatal outcomes 
is largely absent. Of highest concern to many obstetrical providers is "how to" manage pregnant women with chronic pain disorders, and our literature search confirms the need to more clearly define the role(s) of the clinical care team and expand evidence-based data to guide management.

Two reasons are plausible for the limited information on pain disorders during the perinatal period. First, pregnancy in women with chronic pain is rare. This is disputed by the fact that chronic pain is the most common form of chronic illness for people under the age of 60 years, and women are disproportionally impacted. With the increasing rates of women older than 30 years giving birth, clinicians are likely to see women with complex medical problems, such as chronic pain syndromes, experiencing pregnancy. Clinicians may also discount pain complaints during the antenatal period due to the clinical belief that low back pain is a norm of pregnancy. This belief supports the next point. Second, chronic pain syndromes and their treatment during pregnancy are not studied. Past reviews as well as our current review have demonstrated previous investigations. However, data detailing efficacy of treatments, specifically non-pharmacological options, is scant. Third, the available data are difficult to capture. A limitation of our review was the inadequacy of the search terms to capture fully the articles of interest. This displays the difficulty in capturing the limited published information as well as the hazard in getting evidence-based information for busy clinicians.

We feel there is sufficient evidence to support the development of broad guidelines to address the clinical management of chronic pain disorders during the perinatal period by obstetrical care providers. Of note, pregnancy is often an exclusion criterion for many chronic pain programs, and obstetricians are deemed the "de facto" expert in all conditions during pregnancy. As such, a referral to a maternal fetal medicine physician or chronic pain provider is recommended if available. The 2016 Center for Disease Control Guideline for Prescribing Opioids for Chronic Pain ${ }^{151}$ and the Canadian Guideline for the Use of Opioids in the Treatment of Chronic Noncancer Pain ${ }^{17}$ provide a good starting place, but are focused on the use of opioids. Our guidelines were developed to address clinical management by obstetrical care providers of these patients as well as the use of opioids. We intend our guidelines to be a starting point for discussion and hope future research efforts will better define parameters as well as support optimal obstetrical and neonatal outcomes. Guidelines are presented in the following text alongside a level of evidence supporting them (Table 1).
Table I Level of evidence

\begin{tabular}{ll}
\hline Level & Evidence \\
\hline I & Evidence from a systematic review or meta-analysis of all \\
& relevant RCTs (randomized controlled trials) or evidence- \\
& based clinical practice guidelines based on systematic \\
& reviews of RCTs or three or more RCTs of good quality \\
& that have similar results. \\
& Evidence obtained from at least one well-designed RCT \\
II & (eg, large multi-site RCT). \\
& Evidence obtained from well-designed controlled trials \\
III & without randomization. \\
IV & Evidence from well-designed case-control or cohort studies. \\
V & Evidence from systematic reviews of descriptive and \\
& qualitative studies (meta-synthesis). \\
VI & Evidence from a single descriptive or qualitative study. \\
VII & Evidence from the opinion of authorities and/or reports of \\
& expert committees.
\end{tabular}

Abbreviation: RCT, randomized controlled trial.

Guideline \#l:At the initial obstetrical appointment, an appropriate history and physical examination should be completed (Level VII)

Helpful information includes detailed information about the cause of chronic pain; pre-conception treatment history with response; current treatment plan and provider; history of chronic pain during previous pregnancies; and an assessment of comorbid conditions that may complicate treatment, such as depression. Obtaining medical records from previous providers can be helpful to obtain complete and accurate health information. This information will help guide the clinician in the management plan. If collaborating with other providers (ie, chronic pain management teams), it is pertinent to delineate responsibilities (eg, who will prescribe pain medications).

\section{Guideline \#2:All patients should be monitored for alcohol, nicotine, and illicit drug use disorders continuously throughout the perinatal period (Level VII)}

The presence of an alcohol, nicotine, or substance use disorder complicates the management of chronic pain as these individuals are at potential risk for overdoses and abuse of prescription medications. Monitoring includes screening patients; obtaining a urine drug screen at the initial appointment and periodically thereafter; and checking the state's prescription drug monitoring program, if available, at each appointment. Screening can be completed via forms or conversation. Available screening forms include the 4Ps and Car, Relax, Alone, Forget, Friends, Trouble screen (CRAFFT, for women aged 26 years or younger) questionnaires. There is no clear consensus which screening form is optimal for pregnancy. Urine drug screens provide an objective 
and secondary assessment for illicit drug use and should be obtained with consent from the patient. Identification of substance use during pregnancy has potential legal complications, and thus some providers may avoid obtaining urine drug screens. We feel that urine drug screens are a vital aspect of chronic pain management as they help identify exposures that pose a teratogenic risk to fetus as well as maternal risk of overdosing and substance use. Checking the state's prescription drug monitoring program helps verify the patient's history at the initial visit, provides a continuous evaluation of appropriate medication use, and aids in the assessment of a substance use disorder. Any patient with a confirmed or suspected substance use disorder should be referred for an evaluation and/or treatment with an addiction expert. We also advise patients to be cognizant of their inherent concerns for abuse and addiction, including how these concerns may negatively impact their treatment decisions.

\section{Guideline \#3: Collaborate with the patient to establish a treatment goal (Level VII)}

Being free of pain is often not an achievable treatment goal without significant safety hazards during the pregnancy. This will often require providers to be comfortable with a patient's discomfort. We recommend establishing an objective goal, such as an appropriate pain level or allowing a patient to work full time.

\section{Guideline \#4:A management plan should be} formulated that minimizes in utero exposures while maximizing obstetrical and fetal health (Level IV)

Treatments include both non-pharmacological and pharmacological treatments. Non-pharmacological options include acupuncture, chiropractic care, TENS units, spinal cord stimulation, exercise, and transcranial magnetic stimulation. Given the limited amount of information detailing safety and efficacy, we caution the use of non-pharmacological treatment options. Providers should document that the patient has received previous benefit as well as a discussion of the unknown risks of the treatment to both mom and fetus. Pharmacological management should focus on minimizing exposures to the fetus. This can occur by simplification of medication regimens and elimination of medications that pose limited efficacy and/or excessive risk to mom and/or the unborn child (eg, acetaminophen). For example, a patient who is receiving treatment with oxycodone-acetaminophen and morphine prn would be treated with oxycodone monotherapy at effective doses. Some medications may need to be tapered to prevent withdrawal and/or rebound pain. Opioid prescriptions should be tapered to discontinuation if possible as eliminating and/or preventing NAS is a laudable goal. We recognize that not all patients can be managed without opioids and recommend to prescribe them safely (see guidelines in the following text). Antiepileptic drugs are often used to manage chronic pain conditions and require additional folic acid supplementation (eg, $4 \mathrm{mg}$ PO daily) during pregnancy to decrease the risk of neural tube defects. Folic acid supplementation should also be considered with any in utero exposure to antiepileptic drugs during the antepartum period.

\section{Guideline \#5: For opioid prescriptions, clinicians should prescribe at the lowest effective dose and quantity (Level IV)}

We recommend responsible prescribing of opioid medications, and encourage pill counts at each appointment to verify compliance with the prescribed regimen. While the authors agree that excessive use of opioids should be avoided due to overall risk of high doses of opioid, such as death or iatrogenic overdose, opioids should be utilized to effect if they cannot be eliminated from use. In addition, no data demonstrate improved obstetrical or neonatal outcomes with lower doses compared to high doses.

Guideline \#6:A pain management plan for labor and delivery should be formulated in collaboration with the patient (Level V)

Patients with chronic pain disorders often express fear and anxiety of labor and delivery due to the anticipation of pain; thus, these patients benefit from reassurance and recognition of their pain tolerance, hyperanalgesia, and increased analgesic requirements as well as a discussion of pain management at delivery. For patients requiring specialized services from anesthesiology, they may benefit from a consultation prior to delivery. Following a vaginal delivery, patients will benefit from scheduled acetaminophen and ibuprofen. Some patients may require opioids following a vaginal delivery, and almost all will require opioids following an operative delivery. When providing opioids following delivery, patients should receive 3-5 days of higher doses of opioid medications with strict dosage instructions. In the acute postpartum period, a plan for transitioning the patient back to the prior chronic pain management team should be formulated.

\section{Guideline \#7: Clinicians should discuss reproductive} health with any woman with a chronic pain condition and provide counseling as appropriate (Level VII) As half of all pregnancies in the United States are unplanned, this discussion is appropriate at any time during the perinatal period as well as during annual evaluations of non-pregnant patients. Topics include appropriate contraceptive methods 
as well as a risk-benefit discussion of medications during the perinatal period. For women using medications with potential teratogenicity, a daily prenatal vitamin (with additional folic acid if an antiepileptic medication is prescribed) may also be helpful. In general, women of reproductive age managed on antiepileptic drugs should receive folic acid supplementation (eg, minimum of $1 \mathrm{mg}$ PO daily).

\section{Conclusion}

The course and management of chronic pain disorders during the perinatal period is understudied, and obstetrical care providers are typically responsible for pain management. In recognition of the need for more data, we have provided general guidelines for the clinical leadership of these patients during the perinatal period. Cohort studies investigating the treatment of various chronic pain disorders provide the highest level of supporting evidence (ie, Level IV). The lack of well-designed randomized clinical trials as well as systematic reviews and meta-analyses prohibits the practice of evidence-based medicine. Future research should address this need by focusing on the prevalence, course, and optimal management of chronic pain disorders during the antenatal and postpartum period.

\section{Acknowledgment}

We thank Donna Eastham, BA, for her help in editing and submitting this manuscript. This work was supported by the University of Arkansas for Medical Sciences Translational Research Institute (grants ULITR000039 and KL2TR000063) through the NIH National Center for Research Resources and the National Center for Advancing Translational Sciences. The contents are soley the responsibility of the authors and do not necessarily represent the official views of the NIH.

\section{Author contributions}

All authors contributed toward data analysis, drafting and critically revising the paper, gave final approval of the version to be published, and agree to be accountable for all aspects of the work.

\section{Disclosure}

Dr Ray-Griffith currently receives clinical trial support from Neuronetics and has received clinical trial support from Sage Therapeutics. Dr Stowe has received research support from and consulted to GlaxoSmithKleine, Pfizer, and Wyeth Corporations, and received speakers honoraria from the complies, plus from Eli Lilly and Forest Corporations prior to 2008. Dr Stowe received clinical trials support from Janssen Pharmaceuticals and Sage Therapeutics in the past 24 months.

\section{References}

1. What is chronic pain and what are the symptoms? Available from: https://www.webmd.com/pain-management/guide/understanding-painmanagement-chronic-pain\#1. Accessed July 27, 2016.

2. Cogan R, Spinnato JA. Pain and discomfort thresholds in late pregnancy. Pain. 1986;27(1):63-68.

3. Gintzler AR. Endorphin-mediated increases in pain threshold during pregnancy. Science. 1980;210(4466):193-195.

4. Cunningham FG, Leveno KJ, Bloom SL, Hauth JC, Rouse DJ, Spong CY, eds. Williams Obstetrics. 23rd ed. New York: McGraw Medical; 2010.

5. Dørheim SK, Bjorvatn B, Eberhard-Gran M. Insomnia and depressive symptoms in late pregnancy: a population-based study. Behav Sleep Med. 2012;10(3):152-166.

6. Dørheim SK, Bjorvatn B, Eberhard-Gran M. Sick leave during pregnancy: a longitudinal study of rates and risk factors in a Norwegian population. BJOG. 2013;120(5):521-530.

7. Babb M, Koren G, Einarson A. Treating pain during pregnancy. Can Fam Physician. 2010;56(1):25-27.

8. Coluzzi F, Valensise H, Sacco M, Allegri M. Chronic pain management in pregnancy and lactation. Minerva Anestesiol. 2014;80(2):211-224.

9. Jones HE, Friedman CJ, Starer JJ, Terplan M, Gitlow S. Opioid use during pregnancy: an international roadmap for future research and clinical practice. Addict Disord Their Treat. 2014;13(1):8-15.

10. Lalkhen A, Grady K. Non-obstetric pain in pregnancy. Rev Pain. 2008;1(2):10-14.

11. Pritham UA, McKay L. Safe management of chronic pain in pregnancy in an era of opioid misuse and abuse. J Obstet Gynecol Neonatal Nurs. 2014;43(5):554-567.

12. Wunsch MJ, Stanard V, Schnoll SH. Treatment of pain in pregnancy. Clin J Pain. 2003;19(3):148-155.

13. Rathmell JP, Viscomi CM, Ashburn MA. Management of nonobstetric pain during pregnancy and lactation. Anesth Analg. 1997;85(5):1074-1087.

14. Epstein RA, Bobo WV, Martin PR, et al. Increasing pregnancy-related use of prescribed opioid analgesics. Ann Epidemiol. 2013;23(8):498-503.

15. Naik RP, Lanzkron S. Baby on board: what you need to know about pregnancy in the hemoglobinopathies. Hematology Am Soc Hematol Educ Program. 2012;2012:208-214.

16. Pryor JR, Maalouf FI, Krans EE, Schumacher RE, Cooper WO, Patrick SW. The opioid epidemic and neonatal abstinence syndrome in the USA: a review of the continuum of care. Arch Dis Child Fetal Neonatal Ed. 2017;102(2):F183-F187.

17. Kahan M, Wilson L, Mailis-Gagnon A, Srivastava A; National Opioid Use Guideline Group. Canadian guidelines for safe and effective use of opioids for chronic noncancer pain: clinical summary for family physicians. Part 2: special populations. Canadian Family Physician. 2011; 57(11):1269-1276.

18. Broussard CS, Rasmussen SA, Reefhuis J, et al; National Birth Defects Prevention Study. Maternal treatment with opioid analgesics and risk for birth defects. Am J Obstet Gynecol. 2011;204(4):314.e1-314.e11.

19. Hardt N, Wong TD, Burt MJ, Harrison R, Winter W, Roth J. Prevalence of prescription and illicit drugs in pregnancy-associated non-natural deaths of Florida mothers, 1999-2005. J Forensic Sci. 2013;58(6): 1536-1541.

20. Yazdy MM, Mitchell AA, Tinker SC, Parker SE, Werler MM. Periconceptional use of opioids and the risk of neural tube defects. Obstet Gynecol. 2013;122(4):838-844.

21. Taylor JL, McKibben RA, DeCamp M, Chisolm MS. Putting a face on the prescription opioid epidemic: a case report. Gen Hosp Psychiatry. 2014;36(4):449.e1-449.e2.

22. Nezvalová-Henriksen K, Spigset O, Nordeng H. Effects of codeine on pregnancy outcome: results from a large population-based cohort study. Eur J Clin Pharmacol. 2011;67(12):1253-1261.

23. Koren G, Cairns J, Chitayat D, Gaedigk A, Leeder SJ. Pharmacogenetics of morphine poisoning in a breastfed neonate of a codeine-prescribed mother. Lancet. 2006;368(9536):704. 
24. Sharpe C, Kuschel C. Outcomes of infants born to mothers receiving methadone for pain management in pregnancy. Arch Dis Child Fetal Neonatal Ed. 2004;89(1):F33-F36.

25. Kellogg A, Rose CH, Harms RH, Watson WJ. Current trends in narcotic use in pregnancy and neonatal outcomes. Am J Obstet Gynecol. 2011; 204(3):259.e1-259.e4.

26. Bauer AZ, Kriebel D. Prenatal and perinatal analgesic exposure and autism: an ecological link. Environ Health. 2013;12:41.

27. Becker KG, Schultz ST. Similarities in features of autism and asthma and a possible link to acetaminophen use. Med Hypotheses. 2010; 74(1):7-11.

28. Liew Z, Ritz B, Rebordosa C, Lee PC, Olsen J. Acetaminophen use during pregnancy, behavioral problems, and hyperkinetic disorders. JAMA Pediatr. 2014;168(4):313-320.

29. Stergiakouli E, Thapar A, Smith GD. Association of acetaminophen use during pregnancy with behavioral problems in childhood: evidence against confounding. JAMA Pediatr. 2016;170(10):964-970.

30. Thompson JM, Waldie KE, Wall CR, Murphy R, Mitchell EA; ABC Study Group. Associations between acetaminophen use during pregnancy and ADHD symptoms measured at ages 7 and 11 years. PLoS One. 2014;9(9):e108210.

31. Das B, McCrory C. Spinal cord stimulation in pregnancy with failed back surgery syndrome. Ir Med J. 2014;107(4):117-118.

32. Ahmed S, Lindsay JM, Snyder DI. Spinal cord stimulation for complex regional pain syndrome: a case study of a pregnant female. Pain Physician. 2016;19(3):E487-E493.

33. Bernardini DJ, Pratt SD, Takoudes TC, Simopoulos TT. Spinal cord stimulation and the pregnant patient-specific considerations for management: a case series and review of the literature. Neuromodulation. 2010;13(4):270-274.

34. Edelbroek C, Terheggen M. High-frequency spinal cord stimulation and pregnancy: a case report. Neuromodulation. 2015;18(8):757-758.

35. Ito S, Sugiura T, Azami T, Sasano H, Sobue K. Spinal cord stimulation for a women with complex regional pain syndrome who wished to get pregnant. J Anesth. 2013;27:124-127.

36. Fedoroff IC, Blackwell E, Maylsh L, McDonald WN, Boyd M. Spinal cord stimulation in pregnancy: a literature review. Neuromodulation. 2012;15(6):537-541.

37. Segal R. Spinal cord stimulation, conception, pregnancy, and labor: case study in a complex regional pain syndrome patient. Neuromodulation. 1999;2(1):41-45.

38. Saxena A, Eljamel MS. Spinal cord stimulation in the first two trimesters of pregnancy: case report and review of the literature. Neuromodulation. 2009;12(4):281-283.

39. Yoo HS, Nahm FS, Yim KH, Moon JY, Kim YS, Lee PB. Pregnancy in women with spinal cord stimulator for complex regional pain syndrome: a case report and review of the literature. Korean J Pain. 2010;23(4):266-269.

40. Sommerfield D, Hu P, O'Keeffe D, McKeating AK. Caesarean section in a parturient with a spinal cord stimulator. Int J Obstet Anesth. 2010; 19(1):114-117.

41. Young AC, Lubenow TR, Buvanendran A. The parturient with implanted spinal cord stimulator: management and review of the literature. Reg Anesth Pain Med. 2015;40(3):276-283.

42. Ali Sakr Esa W, Toma I, Tetzlaff JE, Barsoum S. Epidural analgesia in labor for a woman with an intrathecal baclofen pump. Int J Obstet Anesth. 2009;18(1):64-66.

43. Badve M, Shah T, Jones-Ivy S, Vallejo MC. Ultrasound guided epidural analgesia for labor in a patient with an intrathecal baclofen pump. Int J Obstet Anesth. 2011;20(4):370-372.

44. Tarshis J, Zuckerman JE, Katz NP, Segal S, Mushlin PS. Labour pain management in a parturient with an implanted intrathecal pump. Can J Anaesth. 1997;44(12):1278-1281.

45. Jones I, Johnson MI. Transcutaneous electrical nerve stimulation. Continuing education in anaesthesia. Crucial Care Pain. 2009;9(4): $130-138$.

46. Byrd LM, Jadoon B, Liberman I, Johnston T. Chronic pain and obstetric management of a patient with tuberous sclerosis. Pain Med. 2007; 8(2):199-203.
47. Mulak A, Tache Y, Larauche M. Sex hormones in the modulation of irritable bowel syndrome. World J Gastroenterol. 2014;20(10): 2433-2448.

48. Trikha A, Baidya DK, Singh PM. Complex regional pain syndrome and pregnancy. J Obstet Anaesth Crit Care. 2012;2:69-73.

49. Sivashanker K, Mufson M, Mittal L, Ross E, Suzuki J. Challenges in managing acute on chronic pain in a pregnant woman at high risk for opioid use disorder in the general hospital setting. Harv Rev Psychiatry. 2015;23(2):157-166.

50. Somerville BW. A study of migraine in pregnancy. Neurology. 1972;22: 824-828.

51. Wood ME, Frazier JA, Nordeng HM, Lapane KL. Prenatal triptan exposure and parent-reported early childhood neurodevelopmental outcomes: an application of propensity score calibration to adjust for unmeasured confounding by migraine severity. Pharmacoepidemiol Drug Saf. 2016;25(5):493-502.

52. Callaghan N. The migraine syndrome in pregnancy. Neurology. 1968; 18:197-201

53. Scharff L, Marcus DA, Turk DC. Headache during pregnancy and in the postpartum: a prospective study. Headache. 1997;37(4):203-210.

54. Granella F, Sances G, Zanferrari C, Costa A, Martignoni E, Manzoni GC. Migraine without aura and reproductive life events: a clinical epidemiology study in 1300 women. Headaches. 1993;33(7):385-389.

55. Marozio L, Facchinetti F, Allais G, et al. Headache and adverse pregnancy outcomes: a prospective study. Eur J Obstet Gynecol Reprod Biol. 2012;161(2):140-143.

56. Facchinetti F, Allais G, Nappi RE, et al. Migraine is a risk factor for hypertensive disorders in pregnancy: a prospective cohort study. Cephalagia. 2008;29:286-291.

57. Amundsen S, Nordeng H, Nezvalova-Henriksen K, Stovner LJ, Spigset O. Pharmacological treatment of migraine during pregnancy and breastfeeding. Nat Rev Neurol. 2015;11(4):209-215.

58. Duong S, Bozzo P, Nordeng H, Einarson A. Safety of triptans for migraine headache during pregnancy and breastfeeding. Can Fam Physician. 2010;56(6):537-539.

59. MacGregor EA. Headache in pregnancy. Neurol Clin. 2012;30(3): 835-866.

60. Jürgens TP, Schaefer C, May A. Treatment of cluster headache in pregnancy and lactation. Cephalalgia. 2009;29(4):391-400.

61. Marcus DA, Scharff L, Turk DC. Nonpharmacological management of headaches during pregnancy. Psychosom Med. 1995;57(6):527-535.

62. Nezvalova-Henriksen K, Spigset O, Nordeng H. Triptan exposure during pregnancy and the risk of major congenital malformations and adverse pregnancy outcomes: results from the Norwegian Mother and Child Cohort Study. Headache. 2010;50:563-575.

63. Kallen B, Lygner PE. Delivery outcome in women who used drugs for migraine during pregnancy with special reference to sumatriptan. Headache. 2001;41:351-356.

64. Olesen C, Steffensen FH, Sorensen HT, Nielsen GL, Olsen J. Pregnancy outcome following prescription for sumatriptan. Headache. 2000; 40:20-24

65. Wood ME, Lapane K, Frazier JA, Ystrom E, Mick EO, Nordeng H. Prenatal triptan exposure and internalising and externalising behaviour problems in 3-year-old children: results from the Norwegian Mother and Child Cohort Study. Paediatr Perinat Epidemiol. 2016;30(2): 190-200.

66. Marmura MJ. Use of dopamine antagonists in treatment of migraine. Curr Treat Options Neurol. 2012;14(1):27-35.

67. Patil S, Willett O, Thompkins T, et al. Botulinum toxin: pharmacology and therapeutics roles in pain states. Curr Pain Headache Rep. 2016; 20(3): 15 .

68. Barrett JH, Brennan P, Fiddler M, Silman AJ. Does rheumatoid arthritis remit during pregnancy and relapse postpartum? Results from a nationwide study in the United Kingdom performed prospectively from late pregnancy. Arthritis Rheum. 1999;42(6):1219-1227.

69. de Man YA, Dolhain RJ, van de Geijn FE, Willemsen SP, Hazes JM. Disease activity of rheumatoid arthritis during pregnancy: results from a nationwide prospective study. Arthritis Rheum. 2008;59(9):1241-1248. 
70. Krause ML, Makol A. Management of rheumatoid arthritis during pregnancy: challenges and solutions. Open Access Rheumatol. 2016; $8: 23-36$.

71. Makol A, Wright K, Amin S. Rheumatoid arthritis and pregnancy: safety considerations in pharmacological management. Drugs. 2011;71(15): 1973-1987.

72. Østensen M, Förger F. Management of RA medications in pregnant patients. Nat Rev Rheumatol. 2009;5(7):382-390.

73. Kuriya B, Hernández-Díaz S, Liu J, Bermas BL, Daniel G, Solomon DH. Patterns of medication use during pregnancy in rheumatoid arthritis. Arthritis Care Res (Hoboken). 2011;63(5):721-728.

74. Bender MA. Sickle cell disease. In: Pagon RA, Adam MP, Ardinger HH, et al, editors. GeneReviews ${ }^{\circledR}$. Seattle, WA: University of Washington; 1993-2016.

75. Poddar D, Maude GH, Plant MJ, Scorer H, Serjeant GR. Pregnancy in Jamaican women with homozygous sickle cell disease. Fetal and maternal outcome. Br J Obstet Gynaecol. 1986;93(7):727-732.

76. Van Enk A, Visschers G, Jansen W, Statius van Eps LW. Maternal death due to sickle cell chronic lung disease. Br J Obstet Gynaecol. 1992;99(2): 162-163.

77. Powars DR, Sandhu M, Niland-Weiss J, Johnson C, Bruce S, Manning PR. Pregnancy in sickle cell disease. Obstet Gynecol. 1986;67(2): 217-228.

78. Smith JA, Espeland M, Bellevue R, Bonds D, Brown AK, Koshy M. Pregnancy in sickle cell disease: experience of the cooperative study of sickle cell disease. Obstet Gynecol. 1996;87(2):199-204.

79. Dauphin-McKenzie N, Gilles JM, Jacques E, Harrington T. Sickle cell anemia in the female patient. Obstet Gynecol Surv. 2006;61(5): 343-352.

80. Koshy M, Burd L, Wallace D, Moawad A, Baron J. Prophylactic redcell transfusions in pregnant patients with sickle cell disease. A randomized cooperative study. $N$ Engl J Med. 1988;319(22):1447-1452.

81. Levy HP. Ehlers-danlos syndrome, hypermobility type. In: Pagon RA, Adam MP, Ardinger HH, et al, editors. GeneReviews ${ }^{\circledR}$. Seattle, WA: University of Washington; 1993-2016.

82. Rosenbaum TY, Padoa A. Managing pregnancy and delivery in women with sexual pain disorders. J Sex Med. 2012;9(7):1726-1735.

83. Johnson NS, Harwood EM, Nguyen RH. You have to go through it and have your children: reproductive experiences among women with vulvodynia. BMC Pregnancy Childbirth. 2015;15:114.

84. Nguyen RH, Stewart EG, Harlow BL. A population-based study of pregnancy and delivery characteristics among women with vulvodynia. Pain Ther. 2012;1(1):2.

85. Mogren IM, Pohjanen AI. Low back pain and pelvic pain during pregnancy: prevalence and risk factors. Spine (Phila Pa 1976). 2005;30(8): 983-991.

86. Vullo VJ, Richardson JK, Hurvitz EA. Hip, knee, and foot pain during pregnancy and the postpartum period. J Fam Pract. 1996;43(1): 63-68.

87. Wang SM, Dezinno P, Maranets I, Berman MR, Caldwell-Andrews AA, Kain ZN. Low back pain during pregnancy: prevalence, risk factors, and outcomes. Obstet Gynecol. 2004;104(1):65-70.

88. Fast A, Shapiro D, Ducommun EJ, Friedmann LW, Bouklas T, Floman Y. Low-back pain in pregnancy. Spine (Phila Pa 1976). 1987;12(4): 368-371.

89. Kristiansson P, Svardsudd K, von Schoultz B. Back pain during pregnancy: a prospective study. Spine (Phila Pa 1976). 1996;21(6): 702-709.

90. Brynhildsen J, Hansson A, Persson A, Hammar M. Follow-up of patients with low back pain during pregnancy. Obstet Gynecol. 1998;91(2):182-186.

91. Gutke A, Ostgaard HC, Oberg B. Predicting persistent pregnancy-related low back pain. Spine (Phila Pa 1976). 2008;33(12):E386-E393.

92. Albert H, Godskesen M, Westergaard J. Prognosis in four syndromes of pregnancy-related pelvic pain. Acta Obstet Gynecol Scand. 2001; 80(6):505-510.

93. To WW, Wong MW. Factors associated with back pain symptoms in pregnancy and the persistent of pain 2 years after pregnancy. Acta Obstet Gynecol Scand. 2003;82(12):1086-1091.
94. Norén L, Ostgaard S, Johansson G, Ostgaard HC. Lumbar back and posterior pelvic pain during pregnancy: a 3-year follow-up. Eur Spine J. 2002;11(3):267-271.

95. LaBan MM, Perrin JC, Latimer FR. Pregnancy and the herniated lumbar disc. Arch Phys Med Rehabil. 1983;64(7):319-321.

96. MacEvilly M, Buggy D. Back pain and pregnancy: a review. Pain. 1996;64(3):405-414.

97. Ostgaard HC, Zetherstrom G, Roos-Hansson E. Back pain in relation to pregnancy: a 6-year follow-up. Spine (Phila Pa 1976). 1997; 22(24):2945-2950.

98. Kvorning N, Holmberg C, Grennert L, Aberg A, Akeson J. Acupuncture relieves pelvic and low-back pain in later pregnancy. Acta Obstet Gynecol Scand. 2004;83(3):246-250.

99. Pennick V, Liddle SD. Interventions for preventing and treating pelvic and back pain in pregnancy. Cochrane Database Syst Rev. 2013; (8):CD001139.

100. Liddle SD, Pennick V. Interventions for preventing and treating lowback and pelvic pain during pregnancy. Cochrane Database Syst Rev. 2015;30(9):CD001139.

101. Stuge B, Hilde G, Vollestad N. Physical therapy for pregnancy-related low back and pelvic pain: a systematic review. Acta Obstet Gynecol Scand. 2003;82(11):983-990.

102. Stuge B, Veierod MB, Laerum E, Vollestad N. The efficacy of a treatment program focusing on specific stabilizing exercises for pelvic girdle pain after pregnancy: a two-year follow-up of a randomized clinical trial. Spine (Phila Pa 1976). 2004;29(10):E197-E203.

103. Elden H, Fagevik-Olsen M, Ostgaard HC, Stener-Victorin E, Hagberg H. Acupuncture as an adjunct to standard treatment for pelvic girdle pain in pregnant women: randomised double-blinded controlled trial comparing acupuncture with non-penetrating sham acupuncture. BJOG. 2008;115(13):1655-1668.

104. Depledge J, McNair PJ, Keal-Smith C, Williams M. Management of symphysis pubis dysfunction during pregnancy using exercise and pelvic support belts. Phys Ther. 2005;85(12):1290-1300.

105. Nilsson-Wikmar L, Holm K, Oijerstedt R, Harms-Ringdahl K. Effect of three different physical therapy treatments on pain and activity in pregnancy women with pelvic girdle pain: a randomized clinical trial with 3, 6, and 12 months follow-up postpartum. Spine (Phila Pa 1976). 2005;30(8):850-856

106. Haugland KR, Rasmussen S, Daltveit AK. Group intervention for women with pelvic girdle pain in pregnancy. A randomized controlled trial. Acta Obstet Gynecol Scand. 2006;85(11):1320-1326.

107. Bayliss AJ, Klene FJ, Gundeck EL, Loghmani MT. Treatment of a patient with post-natal chronic calf pain utilizing instrument-assisted soft tissue mobilization: a case study. J Man Manip Ther. 2011;19(3):127-134.

108. Thomas CT, Napolitano PG. Use of acupuncture for managing chronic pelvic pain in pregnancy. A case report. J Reprod Med. 2000; 45(11):944-946.

109. Eisenach JC, Pan P, Smiley RM, Lavand'homme P, Landau R, Houle TT. Resolution of pain after childbirth. Anesthesiology. 2013; 118(1):143-151.

110. Paterson LQ, Davis SN, Khalife S, Amsel R, Binik YM. Persistent genital and pelvic pain after childbirth. J Sex Med. 2009;6(1):215-221.

111. Eisenach JC, Pan PH, Smiley R, Lavand'homme P, Landau R, Houle TT. Severity of acute pain after childbirth, but not type of delivery, predicts persistent pain and postpartum depression. Pain. 2008;140(1):87-94.

112. Hannah ME, Hannah WJ, Hodnett ED, et al; Term Breech Trial 3-Month Follow-up Collaborative Group. Outcomes at 3 months after planned cesarean vs planned vaginal delivery for breech presentation at term: the international randomized Term Breech Trial. JAMA. 2002;287(14):1822-1831.

113. Hannah ME, Whyte H, Hannah WJ, et al; Term Breech Trial Collaborative Group. Maternal outcomes at 2 years after planned cesarean section versus planned vaginal birth for breech presentation at term: the international randomized Term Breech Trial. Am J Obstet Gynecol. 2004;191(3):917-927.

114. Vermelis JM, Wassen MM, Fiddelers AA, Nijhuis JG, Marcus MA. Prevalence and predictors of chronic pain after labor and delivery. Curr Opin Anaesthesiol. 2010;23(3):295-299. 
115. Lavand'homme P. Chronic pain after childbirth. Curr Opin Anaesthesiol. 2013;26:273-277.

116. Nikolajsen L, Sorensen HC, Jensen TS, Kehlet H. Chronic pain following caesarean section. Acta Anaesthesiol Scand. 2004;48(1): 111-116.

117. Sng BL, Sia AT, Quek K, Woo D, Lim Y. Incidence and risk factors for chronic pain after caesarean section under spinal anaesthesia. Anaesth Intensive Care. 2009;37(5):748-752.

118. Liu TT, Raju A, Boesel T, Cyna AM, Tan SG. Chronic pain after cesarean delivery: an Australian cohort. Anaesth Intensive Care. 2013; 41(4):496-500.

119. Niklassen B, Georgsson Ohmann S, Segerdahl M, Blanck A. Risk factors for persistent pain and its influence on maternal wellbeing after cesarean section. Acta Obstet Gynecol Scand. 2015;94(6):622-628.

120. Declercq E, Cunningham DK, Johnson C, Sakala C. Mothers' reports of postpartum pain associated with vaginal and cesarean deliveries: results of a national survey. Birth. 2008;35(1):16-24.

121. Shahin AY, Osman AM. Parietal peritoneal closure and persistent postcesarean pain. Int J Gynaecol Obstet. 2009;104(2):135-139.

122. Ortner CM, Turk DC, Theodore BR, Siaulys MM, Bollag LA, Laundau R. The Short-Form McGill Pain Questionnaire-Revised to evaluate persistent pain and surgery-related symptoms in healthy women undergoing a planned cesarean delivery. Reg Anesth Pain Med. 2014;39(6):478-486.

123. Kainu JP, Sarvela J, Tiippana E, Halmesmaki E, Korttila KT. Persistent pain after caesarean section and vaginal birth: a cohort study. Int $J$ Obstet Anesth. 2010;19(1):4-9.

124. Turmo M, Echevarria M, Rubio P, Almeida C. Development of chronic pain after episiotomy. Rev Esp Anestesiol Reanim. 2015;62(8): 436-442.

125. Lavand'homme P. Chronic pain after vaginal and cesarean delivery: a reality questioning our daily practice of obstetric anesthesia. Int $J$ Obstet Anesth. 2010;19(1):1-2.

126. Lavand'homme P. Postcesarean analgesia: effective strategies and association with chronic pain. Curr Opin Anaesthesiol. 2006;19(3): 244-248.

127. Richez B, Ouchchane L, Guttmann A, et al. The role of psychological factors in persistent pain after cesarean delivery. J Pain. 2015;16(11): 1136-1146.

128. Ostgaard HC, Roos-Hansson E, Zetherstrom G. Regression of back and posterior pelvic pain after pregnancy. Spine (Phila Pa 1976). 1996; 21(23):2777-2780.

129. Loughnan BA, Carli F, Romney M, Dore CJ, Gordon H. Epidural analgesia and backache: a randomized controlled comparison with intramuscular meperidine for analgesia during labour. Br J Anesth. 2002; 89(3):466-472.

130. de Brito Cançado TO, Omais M, Ashmawi HA, Torres ML. Chronic pain after cesarean section. Influence of anesthetic/surgical technique and postoperative analgesia. Rev Bras Anestesiol. 2012;62(6):762-774.

131. Loos MJ, Scheltinga MR, Roumen RM. Surgical management of inguinal neuralgia after a low transverse Pfannenstiel incision. Ann Surg. 2008;248(5):880-885.

132. Sia AT, Sng BL, Lim EC, Law H, Tan EC. The influence of ATP-binding cassette sub-family B member-1 (ABCB1) genetic polymorphisms on acute and chronic pain after intrathecal morphine for caesarean section: a prospective cohort study. Int J Obstet Anesth. 2010;19(3):254-260.

International Journal of Women's Health

\section{Publish your work in this journal}

The International Journal of Women's Health is an international, peerreviewed open-access journal publishing original research, reports, editorials, reviews and commentaries on all aspects of women's healthcare including gynecology, obstetrics, and breast cancer. The manuscript management system is completely online and includes
133. Landau R, Bollag L, Ortner C. Chronic pain after childbirth. Int $J$ Obstet Anesth. 2013;22(2):133-145.

134. Gizzo S, Andrisani A, Noventa M, et al. Caesarean section: could different transverse abdominal incision techniques influence postpartum pain and subsequent quality of life? A systematic review. PLoS One. 2015;10(2):e0114190.

135. Ghahiry A, Rezaei F, Karimi Khouzani R, Ashrafinia M. Comparative analysis of long-term outcomes of Misgav Ladach technique cesarean section and traditional cesarean section. J Obstet Gynaecol Res. 2012;38(10):1235-1239.

136. Paech MJ, Magann EF, Doherty DA, Verity LJ, Newnham JP. Does magnesium sulfate reduce the short- and long-term requirements for pain relief after caesarean delivery? A double-blind placebo-controlled trial. Am J Obstet Gynecol. 2006;194(6):1596-1602.

137. Ducic I, Moxley M, Al-Attar A. Algorithm for treatment of postoperative incisional groin pain after cesarean delivery or hysterectomy. Obstet Gynecol. 2006;108(1):27-31.

138. Loos MJ, Scheltinga MR, Mulders LG, Roumen RM. The Pfannenstiel incision as a source of chronic pain. Obstet Gynecol. 2008;111(4): 839-846.

139. Gutierrez S, Liu B, Hayashida K, Houle TT, Eisenach JC. Reversal of peripheral nerve injury-induced hypersensitivity in the postpartum period: role of spinal oxytocin. Anesthesiology. 2013;118(1): 152-159.

140. Scriven MW, Jones DA, McKnight L. The importance of pubic pain following childbirth: a clinical and ultrasonographic study of diastasis of the pubic symphysis. JR Soc Med. 1995;88(1):28-30.

141. Niederhauser A, Magann EF, Mullin PM, Morrison JC. Resolution of infant shoulder dystocia with maternal spontaneous symphyseal separation: a case report. J Reprod Med. 2008;53(1):62-64.

142. Senechal PK. Symphysis pubis separation during childbirth. J Am Board Fam Pract. 1994;7(2):141-144.

143. Björklund K, Berström S, Nordstöm ML, Ulmsten U. Symphseal distention in relation to serum relaxin levels and pelvic pain in pregnancy. Acta Obstet Gynecol Scand. 2000;79(4):269-275.

144. Hou Z, Riehl JT, Smith WR, Strohecker KA, Maloney PJ. Severe postpartum disruption of the pelvic ring: report of two cases and review of the literature. Patient Saf Surg. 2011;5(1):2.

145. Musumeci R, Villa E. Symphysis pubis separation during vaginal delivery with epidural anesthesia. Case report. Reg Anesth. 1994; 19(4):289-291.

146. Parker JM, Bhattacharjee M. Images in clinical medicine. Peripartum diastasis of the symphysis pubis. $N$ Engl J Med. 2009;361(19):1886.

147. Henry L. Chiropractic management of postpartum pubic symphysis diastasis: A case report. J Can Chiropr Assoc. 2015;59(1):30-36.

148. Snow RE, Neubert AG. Peripartum pubic symphysis separation: a case series and review of the literature. Obstet Gynecol Surv. 1997; 52(7):438-443.

149. Idrees A. Management of chronic symphysis pubis pain following child birth with spinal cord stimulator. J Pak Med Assoc. 2012;62(1): 71-73.

150. Fitzgerald CM, Plastaras C, Mallinson T. A retrospective study on the efficacy of pubic symphysis corticosteroid injections in the treatment of pubic symphysis pain. Pain Med. 2011;12(12):1831-1835.

151. Dowell D, Haegerich TM, Chou R. CDC Guideline for prescribing opioids for chronic pain - United States, 2016. MMWR Recomm Rep. 2016;65(1):1-49.

\section{Dovepress}

a very quick and fair peer-review system, which is all easy to use Visit http://www.dovepress.com/testimonials.php to read real quotes from published authors. 